Check for updates

Cite this: RSC Adv., 2017, 7, 34624

Received 10th March 2017

Accepted 23rd June 2017

DOI: $10.1039 / \mathrm{c} 7 \mathrm{ra02935g}$

rsc.li/rsc-advances

\section{Biomimetic intrafibrillar silicification of collagen fibrils through a one-step collagen self-assembly/ silicification approach $\uparrow$}

\begin{abstract}
Changmin $\mathrm{Hu}, \mathbb{D D}^{\mathrm{b}}$ Le Yu (D) and Mei Wei ${ }^{\star a b}$
Inspired by the silicification process in nature, intrafibrillar silicified collagen fibrils were successfully fabricated using a biomimetic one-step collagen self-assembly/silicification approach, in which collagen self-assembly and intrafibrillar silicification occurred simultaneously. To the best of our knowledge, it is the first time that intrafibrillar silicified collagen fibrils were formed via a one-step simultaneous approach, where collagen fibrils served as a templating matrix, and poly(allylamine) hydrochloride and sodium tripolyphosphate acted as the respective positive and negative analogs of zwitterionic proteins. By tailoring zwitterionic proteins analogs, silicified collagen fibrils with different microstructures, including core-shell, twisted and banded structures, were achieved. The intrafibrillar silicified collagen fibrils demonstrated significant improvement in osteoblast proliferation compared with apatite mineralized collagen fibrils. These findings open a new avenue for preparation of silicon-containing hierarchical biocomposites for biomedical needs.
\end{abstract}

\section{Introduction}

Silicon is an essential element contributing significantly to the health of bone and cartilage. ${ }^{1}$ It has been discovered that silicon-containing organic-inorganic biocomposites with unique hierarchical structures exist in numerous natural biological systems, such as bone, fish scales, diatom frustules, and spicules of glass sponges..$^{2-5}$ For example, the long spicules of Hyalonema sieboldi demonstrate a perfect hierarchical structure, remarkable optical properties, and excellent durability and flexibility. ${ }^{6}$ More importantly, silicon-containing biomaterials have been found to be osteoinductive for new bone formation and stimulative for neovascularization without supplements of growth factors. ${ }^{7,8}$ Due to the unique properties of the siliconcontaining biomaterials, great enthusiasm has been generated and extensive effort has been made to replicate these materials to be used in different biomedical applications. . $^{6,9,10}$

In recent years, effort has been directed to develop an in-depth understanding of the biosilicification mechanism so as to replicate the process in vitro and thereby fabricate organic-inorganic hybrid biomaterials with a hierarchical structure. Chemical analyses of glass sponge and diatom have shown that fibrillar collagen can serve as templates for silicification, while the highly zwitterionic proteins, such as silaffins, silicateins, and long-chain

${ }^{a}$ Department of Materials Science and Engineering, University of Connecticut, Storrs, CT 06269, USA. E-mail: mei.wei@uconn.edu; Fax: +1-860-486-4745; Tel: +1-860486-5003

${ }^{b}$ Institute of Materials Science, University of Connecticut, Storrs, CT 06269, USA

$\dagger$ Electronic supplementary information (ESI) available. See DOI: 10.1039/c7ra02935g polyamines, are actively involved in the interplay with collagen and the mediation of silicification process. ${ }^{6,11}$ The zwitterionic proteins exhibit both positive charges introduced by the quaternary ammonium groups and negative charges by the phosphorylated serine residues. ${ }^{12}$ The zwitterionic nature of these proteins enables them to form aggregates, which controls the silicification process and silica morphology. ${ }^{13}$ Polyamines have been found to induce silica precipitation in vitro in the presence of polyanions, where polyamines and polyanions act as positive and negative analogs of zwitterionic proteins, respectively. ${ }^{3}$ Despite all the successes in fabrication of silicon-containing biomaterials, an indepth understanding of the mechanism of biomimetic silicification process has not yet been achieved.

A variety of silicified collagen hybrids have been produced, such as silica-collagen xerogels, and silicified collagen hydrogels with different silicon sources (silica and silicates). ${ }^{14-18}$ Typically, silica is formed on the surface of collagen fibrils (extrafibrillar silicification), resulting in a weak bond between silica and collagen..$^{14,15,19}$ However, the recent successes in intrafibrillar calcification of collagen fibrils have shed light on the understanding of intrafibrillar silicification (forming silica within collagen fibrils), as intrafibrillar calcification and silicification of collagen fibrils may share a similar mechanism. In our previous work, intrafibrillar calcified collagen fibrils have been achieved by a one-step collagen self-assembly and calcification approach. ${ }^{20,21}$ In the present study, we also propose to produce intrafibrillar silicified collagen fibrils via a one-step collagen self-assembly/ silicification (OCSS) approach, where collagen self-assembly and silicification occur simultaneously with the aid of positive and negative analogs of zwitterionic proteins. To test this hypothesis, a systemic study was conducted to investigate the effect of 
zwitterionic proteins analogs on the OCSS approach, and an in vitro cell culture study was also conducted to test the biocompatibility of the intrafibrillar silicified collagen fibrils.

\section{Materials and methods}

\subsection{Materials}

Type I collagen was extracted from rat tails, purified based on the protocol reported by Rajan et al..$^{22}$ Poly(allylamine) hydrochloride (PAH, $\left.M_{\mathrm{w}}=15000 \mathrm{Da}\right)$ and sodium tripolyphosphate (TPP) were purchased from Sigma-Aldrich. All chemicals were of analytical chemical grade.

\subsection{Preparation of hydrolyzed silicic acid}

A $3 \mathrm{wt} \%$ hydrolyzed silicic acid stock solution was prepared as followed: Silbond $\circledast 40$ (40\% hydrolyzed tetraethyl orthosilicate (TEOS); Silbond Corp., Weston, MI, USA), absolute ethanol, deionized water (DIW) and $37 \% \mathrm{HCl}$ were mixed at a molar ratio of $1.03: 199: 6.11: 0.03$ and stirred for 1 hour at room temperature to hydrolyze TEOS into orthosilicic acid and its oligomers. ${ }^{23}$

\subsection{Preparation of PAH-stabilized silica (PAH-SA) precursors}

PAH-stabilized silica (PAH-SA) precursors were prepared by the following procedure: a solution with a PAH concentration of $0.267 \mathrm{mM}$ was mixed with $3 \mathrm{wt} \%$ silicic acid at a $1: 1$ volume ratio to obtain $1.5 \mathrm{wt} \%$ silicic acid stabilized by $\mathrm{PAH}$. After stirring for $1 \mathrm{~min}$, the mixture was centrifuged at $3000 \mathrm{rpm}$ and $25^{\circ} \mathrm{C}$ for $10 \mathrm{~min}$. The $\mathrm{PAH}$-stabilized silica ( $\mathrm{PAH}-\mathrm{SA})$ precursors were then collected. ${ }^{24}$

\subsection{Preparation of biomimetic silicified collagen fibrils via an OCSS approach}

Buffer solution was used to avoid sudden $\mathrm{pH}$ changes and prepared based on our established protocol, ${ }^{\mathbf{2 0 2 5}}$ where $184.8 \mathrm{mM} \mathrm{NaCl}, 6.3 \mathrm{mM} \mathrm{K} \mathrm{HPO}_{4} \cdot 3 \mathrm{H}_{2} \mathrm{O}$ and $100.7 \mathrm{mM}$ HEPES (4-(2-hydroxyethyl)piperazine-1-ethane-sulfonic acid) were added to DIW in the order listed above.

Collagen-silica (Col-SA) fibrils. Type I collagen stock solution $\left(4.5 \mathrm{mg} \mathrm{mL}^{-1}\right)$ was diluted to a given concentration $(0.3 \mathrm{mg}$ $\mathrm{mL}^{-1}$ ) using buffer solution at $4{ }^{\circ} \mathrm{C}$. Then different amounts of silicic acid solution ( $3 \mathrm{wt} \%$ ) were added dropwise to the diluted collagen solution immediately with vigorous stirring. The amount of silicic acid added was controlled at a SA/Col ratio of $1: 2,1: 1,2: 1,3: 1$ and $4: 1$. After mixing the diluted collagen solution with the silicic acid solution and stirring for $5 \mathrm{~min}$, the mixtures $(\mathrm{pH}=6.4)$ were incubated at $25{ }^{\circ} \mathrm{C}$ for $10 \mathrm{~min}$, and then incubated in a water bath at $37^{\circ} \mathrm{C}$ for $24 \mathrm{~h}$.

Collagen-poly(allylamine) hydrochloride-silica (Col-PAHSA) fibrils. Type I collagen stock solution $\left(4.5 \mathrm{mg} \mathrm{mL} \mathrm{mb}^{-1}\right)$ was diluted to a given concentration $\left(0.3 \mathrm{mg} \mathrm{mL}^{-1}\right)$ using the buffer solution at $4{ }^{\circ} \mathrm{C}$. Then different amounts of PAH-SA precursors were added dropwise into the diluted collagen solution immediately with vigorous stirring. The amount of PAH-SA precursors was controlled at a SA/Col ratio of $1: 1,4: 3$ and $2: 1$.
Higher ratios of $\mathrm{SA} / \mathrm{Col}$ were not used since precipitates formed rather quickly when the ratios of SA/Col were $3: 1$ and $4: 1$. After mixing the diluted collagen solution with PAH-SA precursors and stirring for $5 \mathrm{~min}$, Col-PAH-SA mixtures $(\mathrm{pH}=$ 6.4) were incubated at $25^{\circ} \mathrm{C}$ for $10 \mathrm{~min}$, and then transferred to a water bath at $37^{\circ} \mathrm{C}$ for $24 \mathrm{~h}$.

Intrafibrillar silicified collagen (Col-inSA) fibrils. Type I collagen stock solution $\left(4.5 \mathrm{mg} \mathrm{mL}^{-1}\right)$ was diluted to a given concentration $\left(0.3 \mathrm{mg} \mathrm{mL}^{-1}\right)$ using the buffer solution at $4{ }^{\circ} \mathrm{C}$. TPP $(1.2 \mathrm{wt} \%)$ was added to this diluted collagen solution and stirred for $5 \mathrm{~min}$. Different amounts of PAH-SA precursors were then added dropwise into this collagen-TPP solution with vigorous stirring. The amount of $\mathrm{PAH}-\mathrm{SA}$ precursors was controlled at a SA/ Col ratio of $1: 1,4: 3$ and $2: 1$. After stirring for $5 \mathrm{~min}$, collagen containing mixtures $(\mathrm{pH}=6.8)$ were incubated at $25^{\circ} \mathrm{C}$ for $10 \mathrm{~min}$, and then transferred to a water bath at $37^{\circ} \mathrm{C}$ for $24 \mathrm{~h}$.

\subsection{Preparation of silicified collagen fibrils via a two-step approach}

Firstly, collagen fibrils without mineralization were produced by the following procedure: type I collagen stock solution $(4.5 \mathrm{mg}$ $\left.\mathrm{mL}^{-1}\right)$ was diluted to a given concentration $\left(0.3 \mathrm{mg} \mathrm{mL}^{-1}\right)$ using the buffer solution at $4{ }^{\circ} \mathrm{C}$, followed by incubation at $25{ }^{\circ} \mathrm{C}$ for $10 \mathrm{~min}$ and then in a water bath at $37^{\circ} \mathrm{C}$ for another $24 \mathrm{~h}$ to precipitate collagen fibrils. Secondly, the collagen fibrils without mineralization were silicified by incubating in silica precursors, which was described below. Col-SA fibrils via a twostep approach ( $T-C o l-S A)$ : silicic acid was added dropwise to the collagen fibrils at a SA/Col ratio of $4: 1$, and then incubated at $37^{\circ} \mathrm{C}$ for another $24 \mathrm{~h}$. Col-PAH-SA fibrils via a two-step approach (T-Col-PAH-SA): PAH-SA precursors were added to the selfassembled collagen fibrils at a SA/Col ratio of $4: 3$, and then incubated at $37{ }^{\circ} \mathrm{C}$ for $24 \mathrm{~h}$. Col-inSA fibrils via a two-step approach (T-Col-inSA): TPP was dissolved in the selfassembled collagen fibrils at a concentration of $1.2 \mathrm{wt} \%$, and $\mathrm{PAH}-\mathrm{SA}$ precursors $(\mathrm{SA} / \mathrm{Col}=4: 3)$ were added after $5 \mathrm{~min}$. The mixed solution was then incubated at $37^{\circ} \mathrm{C}$ for $24 \mathrm{~h}$.

\subsection{Transmission electron microscopy (TEM)}

Silicified collagen fibrils and collagen fibrils without mineralization were dropped onto Formvar carbon coated copper grids, rinsed with DIW and then dried at room temperature. TEM (JEOL, JEM-2010) was used to examine the silicification of collagen fibrils at an accelerating voltage of $80 \mathrm{kV}$. All samples were examined without staining.

\subsection{Field emission scanning electron microscopy (FESEM)}

FESEM (JEOL JSM-6335F, Japan) was used to characterize the surface morphology of the silicified collagen fibrils. Different silicified collagen fibrils were sputter-coated with gold and examined using FESEM operating at $8-10 \mathrm{kV}$.

\subsection{Thermogravimetric analysis (TGA)}

TGA was performed using a Q500 TGA analyzer (TGAQ-500, TA Instrument, New Castle, DE, USA). About $20 \mathrm{mg}$ freeze-dried 
silicified collagen fibrils were placed in a platinum pan and heated from 30 to $900{ }^{\circ} \mathrm{C}$ at a rate of $10{ }^{\circ} \mathrm{C} \min ^{-1}$ in air to determine the amount of minerals in the silicified collagen fibrils.

\subsection{Attenuated total reflection-Fourier transform infrared spectroscopy (ATR-FTIR)}

The freeze-dried silicified collagen fibrils were characterized using ATR-FTIR. A Nicolet Magna 560 FT-IR spectrophotometer (Artisan Technology Group ${ }^{\circledR}$, Illinois, USA) with an ATR setup was used to collect infrared spectra in the range $4000-400 \mathrm{~cm}^{-1}$ at a $4 \mathrm{~cm}^{-1}$ resolution, 32 scans.

\subsection{In vitro cell culture and proliferation}

Mouse calvaria 3T3-E1 (MC3T3-E1, ATCC, USA) cell line, an osteoblast precursor cell line, was used to determine the cytocompatibility of various samples. MC3T3-E1 cells were plated in a culture flask (FALCON, USA) containing $10 \mathrm{~mL}$ of $\alpha$-minimum essential medium ( $\alpha$-MEM; Gibco, Invitrogen, Inc., USA), which was supplemented with $10 \%$ fetal bovine serum (FBS; Gibco, Invitrogen, Inc., USA) and 1\% penicillin-streptomycin (Gibco, Invitrogen, Inc., USA). In a humidified atmosphere of $5 \% \mathrm{CO}_{2}$ under $37{ }^{\circ} \mathrm{C}$ that maintained by an incubator (NAPCO, USA), cells were cultured and further passaged when reaching $80-90 \%$ confluence. The fibrous membranes of $5.5 \mathrm{~mm}$ in diameter were collected and cross-linked with 1 wt\% EDC (1-ethyl-3-(3-dimethylaminopropyl)-carbodiimide). Collagenapatite membrane with an apatite content of about $67 \mathrm{wt} \%$ was produced using a co-precipitation approach, which serves as a control. The cross-linked fibrous membranes were sterilized and placed in a 96-well plate.
To assess cell proliferation and viability using alamarBlue assay, cells were seeded on various samples (four replicates) in 96-well plates at a cell density of 8000 cells per well in $100 \mu \mathrm{L}$ cell culture medium. The cells were cultured for 14 days and the cell culture medium was refreshed every 2 days. After incubating for 1 day, samples that attached with cells were transferred to a new 96-well plate to leave behind the cells escaped from samples. Phenol-red-free cell culture medium with 10\% alamarBlue (Thermo Scientific, USA) was added to each well. After culturing for another $4 \mathrm{~h}, 100 \mu \mathrm{L}$ of the culture solution from each well was transferred to a new 96-well plate to measure the absorbance at wavelengths of $570 \mathrm{~nm}$ and $600 \mathrm{~nm}$ by a microplate reader (BioTek, USA). The samples were then rinsed against PBS twice to remove residue alamarBlue, and $100 \mu \mathrm{L}$ fresh cell culture medium was added to each well and refreshed every other day. After culturing for 4, 7, 10, and 14 days, cell viabilities were investigated according to the procedure descripted above. Percentage of reduction of alamarBlue was calculated according to the instruction provided by the assay.

\subsection{Statistical analysis}

Statistically significant differences $(p)$ between various groups were measured using two-way RM ANOVA analysis of variance that carried out by GraphPad Prism 5.

\section{Results and discussion}

\subsection{Col-SA fibrils}

Silicified collagen fibrils with a core-shell structure are successfully produced using a one-step approach. When silicic acid is mixed with collagen molecules with a SA/Col ratio of

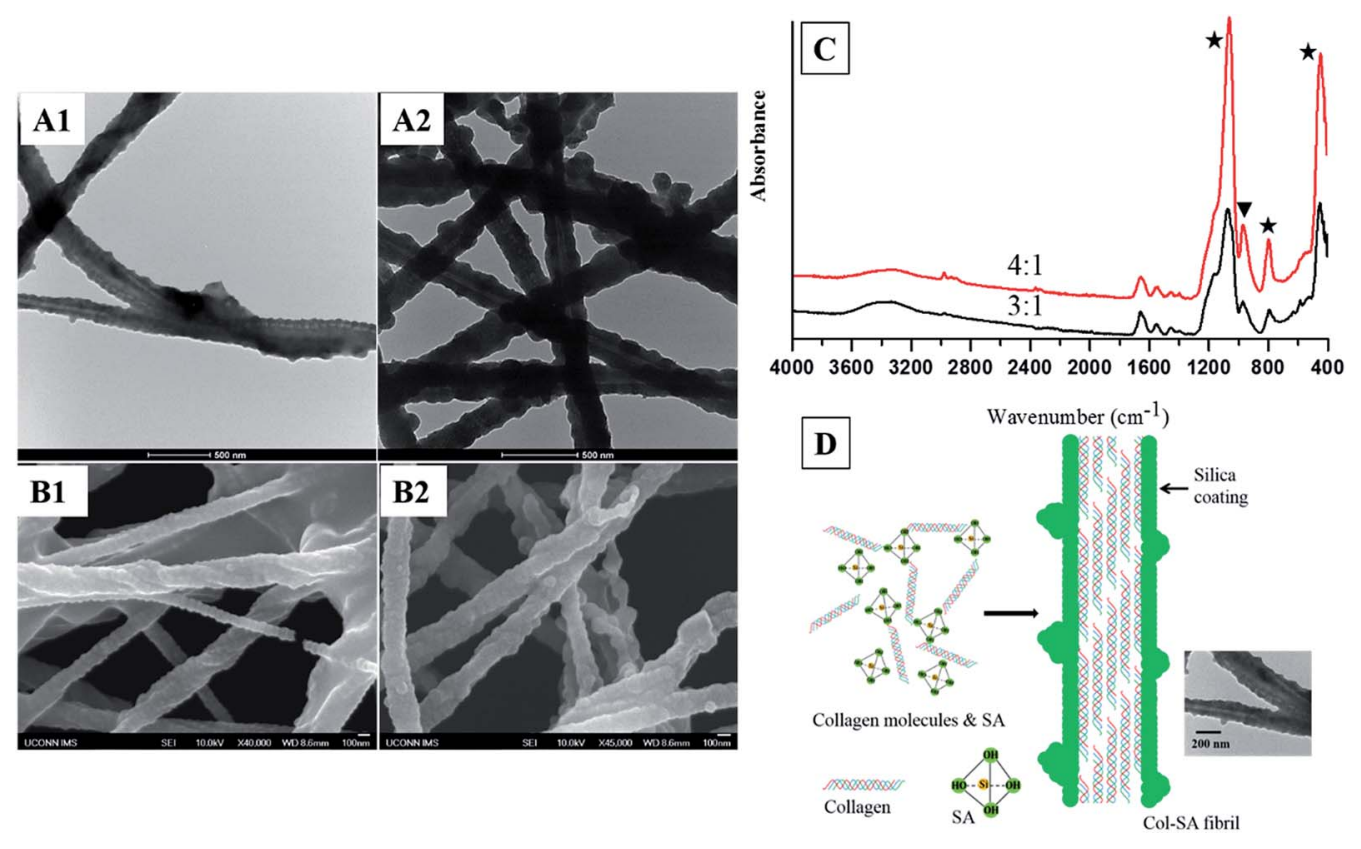

Fig. 1 TEM images (A1 and A2), FESEM images (B1 and B2) of Col-SA fibrils with different SA/Col ratios: $3: 1$ (A1, B1), $4: 1$ (A2, B2). ATR-FTIR spectra (C) of $\mathrm{Col}-\mathrm{SA}$ fibrils (stars indicate the peaks for $\mathrm{Si}-\mathrm{O}-\mathrm{Si}$, and triangle shows the peak for $\mathrm{Si}-\mathrm{OH}$ ). Schematic illustration (D) of the process to form Col-SA fibrils, and the TEM image shows Col-SA fibrils with a SA/Col ratio of $3: 1$. 
$3: 1$ or $4: 1$, a thick layer of dense silica is coated on the collagen fibrils, forming a core-shell structured Col-SA hybrid (Fig. 1A1, A2, B1 and B2). This result is in accordance with the reports by Eglin et al. and Ono et al., where hollow silica fibrils were produced with silica coated onto the surface of templating collagen fibrils. ${ }^{26,27}$ Some Col-SA fibrils also demonstrate a twisted structure, which is due to the presence of negatively charged silanol groups of silica coating on the surface of ColSA hybrid (Fig. 1B1, B2, and C).$^{9,28}$ When the SA/Col ratio is low (1:2, $1: 1$, or $2: 1)$, silicified collagen fibrils with core-shell structures are not formed (data not shown). When the SA/Col ratio is $3: 1$, the distance between two adjacent protrusions is $66.9 \pm 5.8 \mathrm{~nm}(n=30$, Fig. $1 \mathrm{~A} 1$ and B1), which is identical to the distance of the gap zone present in collagen fibrils $(67 \mathrm{~nm})$, indicating the templating function of collagen fibrils. Negatively charged silicic acid preferentially accumulates at sites of highly positively charged gap zone of collagen fibrils, leading to the formation of protrusions with a periodicity of about $67 \mathrm{~nm}$ (Fig. 1D). ${ }^{15,29}$ When the SA/Col ratio is $4: 1$, the shell thickness of the Col-SA core-shell structure increases, and the periodicity of the distinguished protrusions increases to 82.7 $\pm 21.0 \mathrm{~nm}(n=40$, Fig. $1 \mathrm{~A} 2$ and B2). This is due to that with the increase of the $\mathrm{SA} / \mathrm{Col}$ ratio, more and more silica precipitates on the surface of collagen fibrils, resulting in an increase in shell thickness and a decrease in electrostatic attraction between silicic acid and the gap zone of collagen fibrils. As a result, the surface of the coating was smoothened, and some adjacent protrusions fused together, leading to a longer distance between two adjacent protrusions (Fig. 1A2 and B2).

\subsection{Col-PAH-SA fibrils}

By controlling the silica precursors, twisted silicified collagen fibrils with bandings are produced (Fig. 2). A long-chain polyamine (poly(allylamine) hydrochloride (PAH, $\left.M_{\mathrm{w}}=15000 \mathrm{Da}\right)$ ) was used to stabilize silica by the formation of hydrogen bonds with silanol groups of silicic acid, which reduces the availability of silicic acid from forming polysilicic acid, and thereby leads to the formation of fluidic PAH-SA nanoprecursors. ${ }^{4}$ Rope-like, twisted silicified collagen fibrils are formed via a one-step approach by mixing $\mathrm{PAH}-\mathrm{SA}$ precursors and collagen molecules (Fig. 2A-D). This result is in agreement with the reports by Desimone et al. and Heinemann et al., ${ }^{\mathbf{9}, 28}$ where twisted fibrils were formed due to the presence of negatively charged silanol groups of silica (Fig. 2D). The average distances of two adjacent bandings for Col-PAH-SA fibrils are $143.3 \pm 12.1 \mathrm{~nm}, 145.8 \pm$ $7.5 \mathrm{~nm}$, and $145.0 \pm 11.8 \mathrm{~nm}$ for SA/Col ratio of $1: 1,4: 3$ and $2: 1$, respectively (Fig. $2 \mathrm{~A}-\mathrm{C}, n=30$ ). All the banding distances are significantly larger than that of the typical D-banding of collagen fibrils $(67 \mathrm{~nm})$. This may be due to that the amine groups of $\mathrm{PAH}$ in $\mathrm{PAH}-\mathrm{SA}$ precursors interact with carboxyl groups of collagen molecules during the self-assembly of collagen fibrils, where $\mathrm{PAH}$ is inserted between two adjacent collagen molecules as a space linker, leading to a longer distance between adjacent gap zones (Fig. 2E). In PAH-SA precursors, silica is stabilized by $\mathrm{PAH}$ through ionic bonding and/or hydrogen bonding. ${ }^{4}$ Subsequently, PAH-SA precursors infiltrate into collagen fibrils along with $\mathrm{PAH}$ during the collagen fibril formation process. $\mathrm{PAH}$ is then separated from

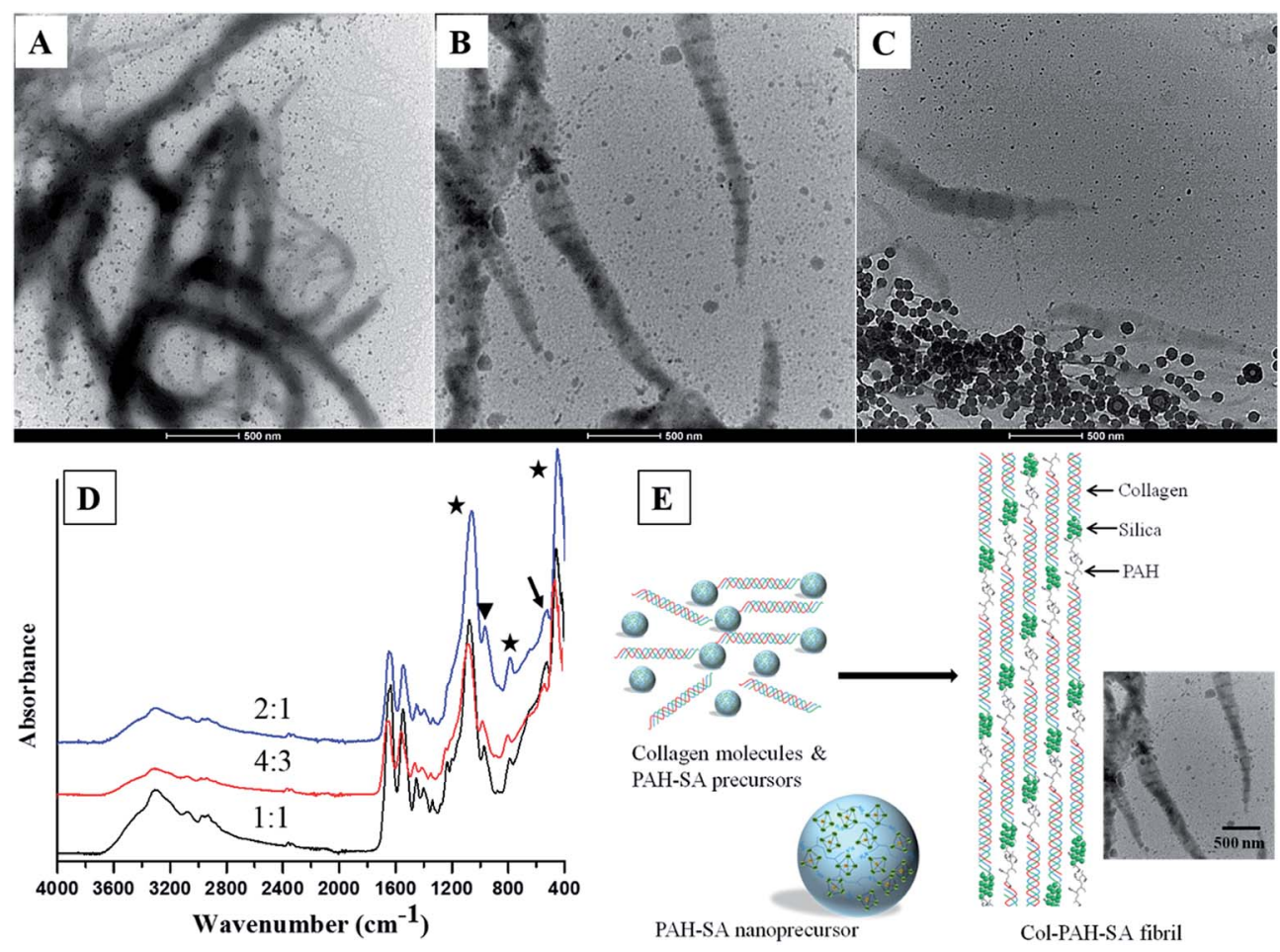

Fig. 2 TEM images of Col-PAH-SA fibrils with different SA/Col ratios: $1: 1$ (A), $4: 3$ (B), and $2: 1$ (C). ATR-FTIR spectra (D) of Col-PAH-SA fibrils (stars indicate the peaks for $\mathrm{Si}-\mathrm{O}-\mathrm{Si}$, triangle shows the peak for $\mathrm{Si}-\mathrm{OH}$, and arrow indicates amine hydrogen bonding). Schematic illustration (E) of the process to form Col-PAH-SA fibrils, and the TEM image shows Col-PAH-SA fibrils with a SA/Col ratio of $4: 3$. 
silicic acid, leading to the precipitation of silica at the $\mathrm{C}$ terminus of collagen molecules, where the potential energy is the lowest. ${ }^{29}$ This explains why the banding in Fig. 2 is larger than that of the typical collagen D-banding because of the longer distance between adjacent gap zones of the fibrils and the precipitation of electron-dense minerals at the C-terminus of collagen molecules. The FTIR result also confirms the attachment of PAH onto collagen fibrils (Fig. 2D). The $528 \mathrm{~cm}^{-1}$ peak of FT-IR is assigned to the amine hydrogen bonding of $\mathrm{PAH}$, indicating the attachment of $\mathrm{PAH}$ onto the silicified collagen fibrils (Fig. 2D).

\subsection{Col-inSA fibrils}

As shown in Fig. 3, intrafibrillar silicified collagen fibrils were produced using PAH and TPP as the positive and negative analogs of zwitterionic proteins, respectively. Compared to ColPAH-SA fibrils, the morphology of collagen fibrils in the ColinSA group exhibits a normal structure instead of twisted fibrils (Fig. 3, ESI, Fig. S1 $\dagger$ ). ${ }^{20}$ This may be due to the competition between TPP and PAH to interact with collagen molecules during the collagen self-assembly process. As a penta-anion, TPP has a stronger electrostatic attraction to the gap zone of collagen fibrils than PAH, leading to prohibition of further bonding of collagen molecules with PAH. Instead, fluidic PAHSA precursors infiltrate into the collagen fibrils and precipitate within the gap zone (Fig. 5). Clear D-bandings are observed using TEM due to electron-dense silica precipitating within specific sites of collagen fibrils (Fig. 3 and 4). As shown in Fig. 3, the D-banding becomes more and more obvious with the increase of SA/Col ratios, and silica nanoparticles are also formed on the surface of collagen fibrils. Similar to silaffins and long-chain polyamines in diatoms, PAH and TPP have been used as respective positive and negative analogs of highly zwitterionic proteins to promote silica formation in vitro. ${ }^{30}$ In details, PAH mimics the positively charged groups of lysine residues in silaffins, while TPP mimics the negatively charged groups introduced by phosphorylation of serine residues., ${ }^{3,31}$ Similar to the mechanism of calcium phosphate intrafibrillar

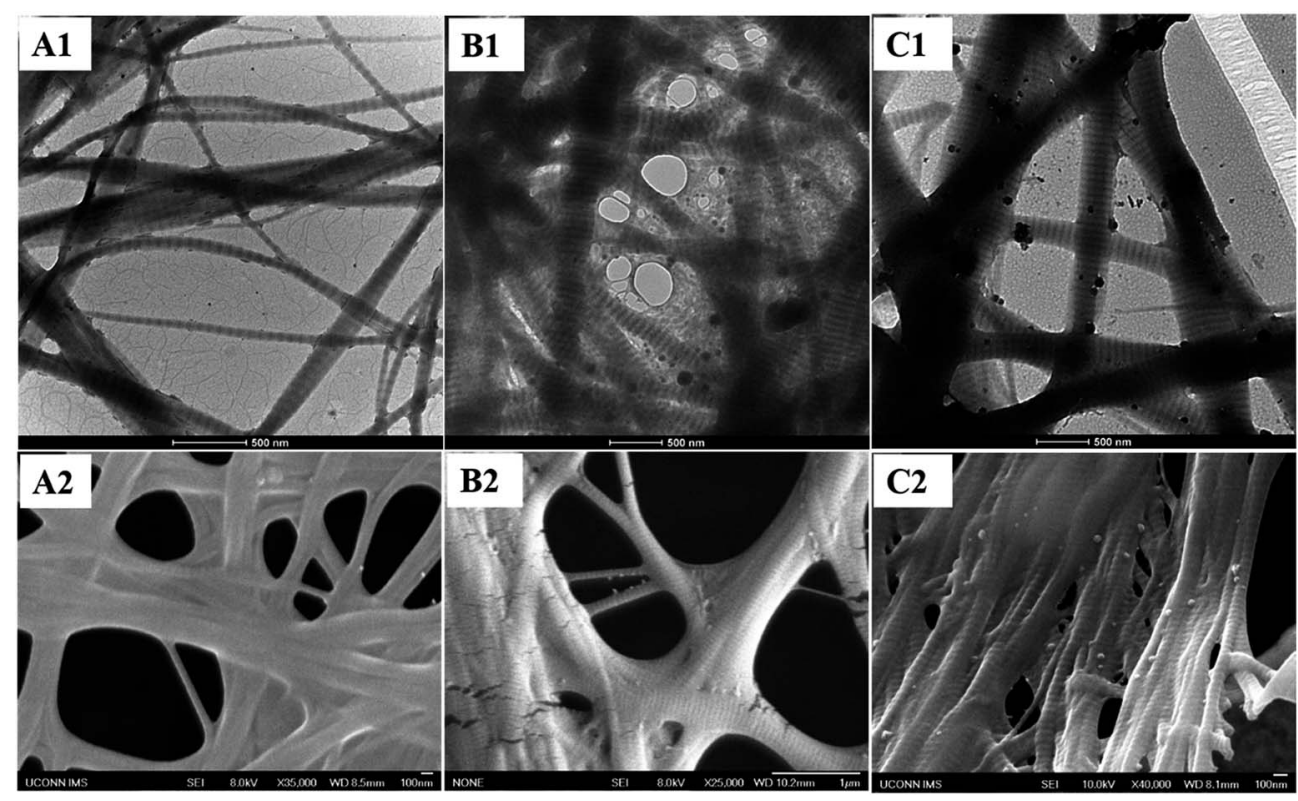

Fig. 3 TEM images (A1, B1, and C1) and FESEM images (A2, B2, and C2) of Col-inSA fibrils with different SA/Col ratios: $1: 1$ (A1, A2), $4: 3$ (B1, B2), and $2: 1(\mathrm{C} 1, \mathrm{C} 2)$.
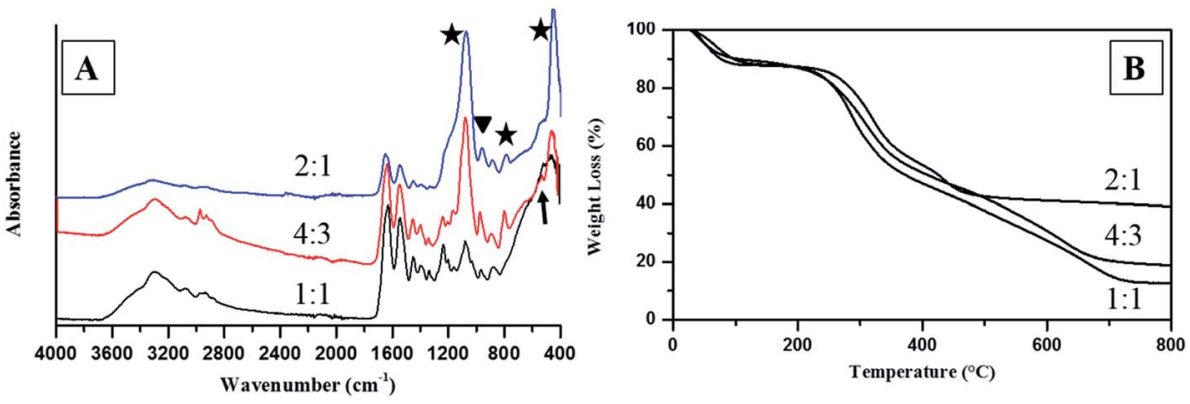

Fig. 4 ATR-FTIR spectra (A) and TGA spectra (B) of Col-inSA fibrils with different SA/Col ratios. (Stars indicate the peaks for Si-O-Si, triangle shows the peak for $\mathrm{Si}-\mathrm{OH}$, and arrow indicates amine hydrogen bonding.) 


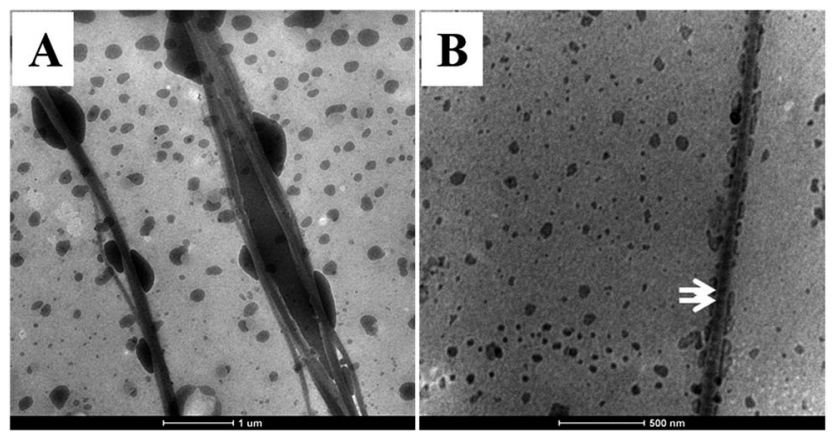

Fig. 5 The initial stage of $\mathrm{PAH}-\mathrm{SA}$ precursors interacted with collagen fibrils in the presence of TPP as a regulator. Low (A) and high (B) magnification of the fluidic silica precursors infiltrated into the collagen fibrils during the collagen self-assembly process. White arrows in B: vague D-banding can be observed.

mineralization, TPP accumulates in the gap zone of collagen fibrils due to electrostatic attraction between the highly negatively charged TPP and the positively charged gap zone of collagen fibrils. ${ }^{20,29}$ TPP further attracts fluidic PAH-SA nanoprecursors to infiltrate into gap zones of collagen fibrils via electrostatic attraction and capillary action (Fig. 5 and 6).,32,33 PAH promotes silica precipitation in the presence of TPP in the gap zone of collagen fibrils, leading to intrafibrillar silicification of collagen fibrils (Fig. 6)..$^{31,34}$

\subsection{Silicified collagen fibrils via a two-step approach}

Moreover, silicification of collagen fibrils via a one-step approach was compared with a two-step approach. In a twostep approach, collagen fibrils were first self-assembled, and then silica precursors were added to the self-assembled collagen fibril suspension to enable the silicification of the precipitated collagen fibrils. Compared T-Col-SA fibrils with Col-SA fibrils at the same $\mathrm{SA} / \mathrm{Col}$ ratio $(\mathrm{SA} / \mathrm{Col}=4: 1)$, silica particles rather than a continuous coating are deposited on the surface of collagen fibrils (Fig. 7A1 and A2). Silica particles may be absorbed onto the collagen fibrils due to electrostatic attraction, or through hydrogen bonding between silanol groups of silica and amine or hydroxyl groups of collagen. ${ }^{6}$ In the T-Col-PAHSA fibrils, silica particles are only formed on the surface of collagen fibrils, while twisted silicified collagen fibrils are formed in Col-PAH-SA fibrils using one-step approach (Fig. 7B1 and B2, ESI, Fig. S1 $\dagger$ ). The comparison between T-Col-PAH-SA and Col-PAH-SA fibrils indicates that in the one-step approach $\mathrm{PAH}$ and silica are well integrated into the collagen selfassembly process and that the silicification and self-assembly of collagen fibrils occur simultaneously. In contrast, intrafibrillar silicification was observed in the Col-inSA fibrils formed via both the two-step and the one-step processes (Fig. 7C1 and C2). In both the two-step and the one-step approaches, highly negatively charged TPP accumulates in the positively charged gap zone of collagen fibrils through electrostatic attraction, which further attracts fluidic PAH-SA precursors to infiltrate into collagen fibrils. ${ }^{4,29,31} \mathrm{PAH}$ and TPP function as the positive and negative analogs of zwitterionic proteins, respectively, which mediate the biosilicification process in nature systems. Similarly, the accumulation of PAH-SA and TPP in the gap zone of collagen fibrils enables the PAH-SA precursors to aggregate and form silica within collagen fibrils., ${ }^{3,13}$

Two kinds of polyanions were used: phosphate ions and TPP, but they have different functions. TPP inhibits the incorporation of PAH during the collagen self-assembly process (Fig. 7B2 and $\mathrm{C} 2$ ), and it also functions as a regulator to guide precise deposition of silica within collagen fibrils (Fig. 5B and 7B1 and C1). Phosphate ions, being one kind of kosmotrope anions, were used to favor collagen self-assembly. ${ }^{16}$ The comparison between T-Col-PAH-SA and T-Col-inSA fibrils indicates that, even though both phosphate ions and TPP induce phase separation of PAH-SA precursors, ${ }^{34,35}$ phosphate ions do not function as a regulator to attract $\mathrm{PAH}-\mathrm{SA}$ to infiltrate into collagen fibrils (Fig. 7B1), but TPP does (Fig. 7C1).

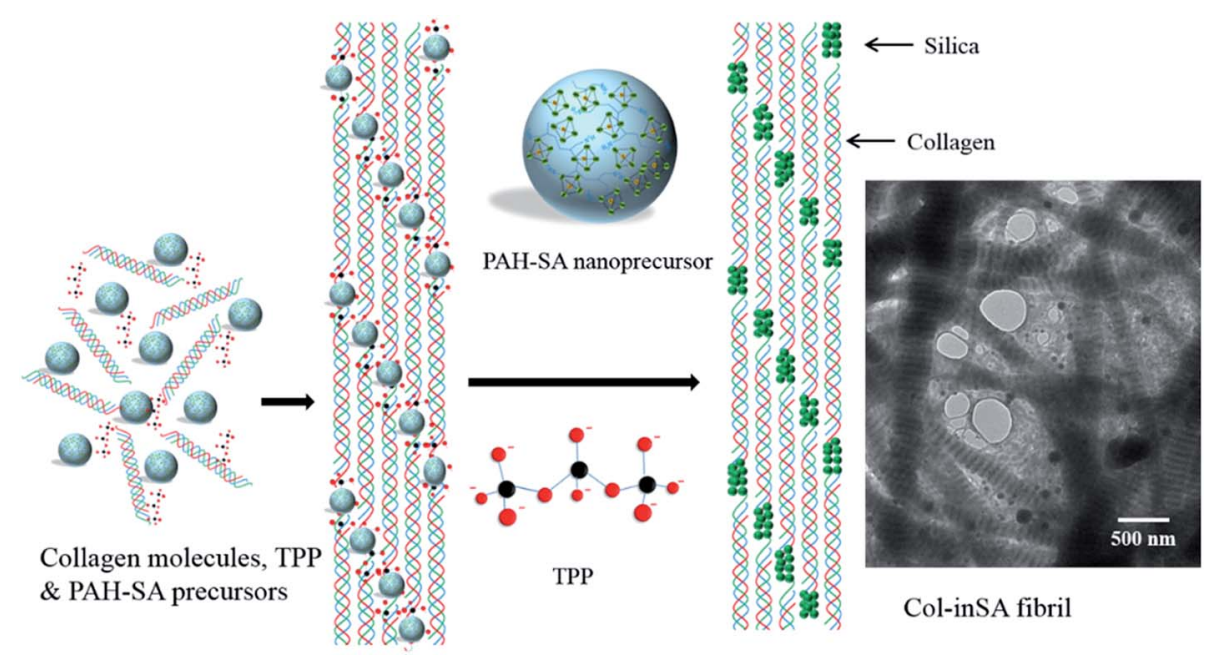

Fig. 6 Schematic illustration of the intrafibrillar mineralization process of Col-inSA fibrils. TEM image shows Col-inSA fibrils with a SA/Col ratio of $4: 3$. 

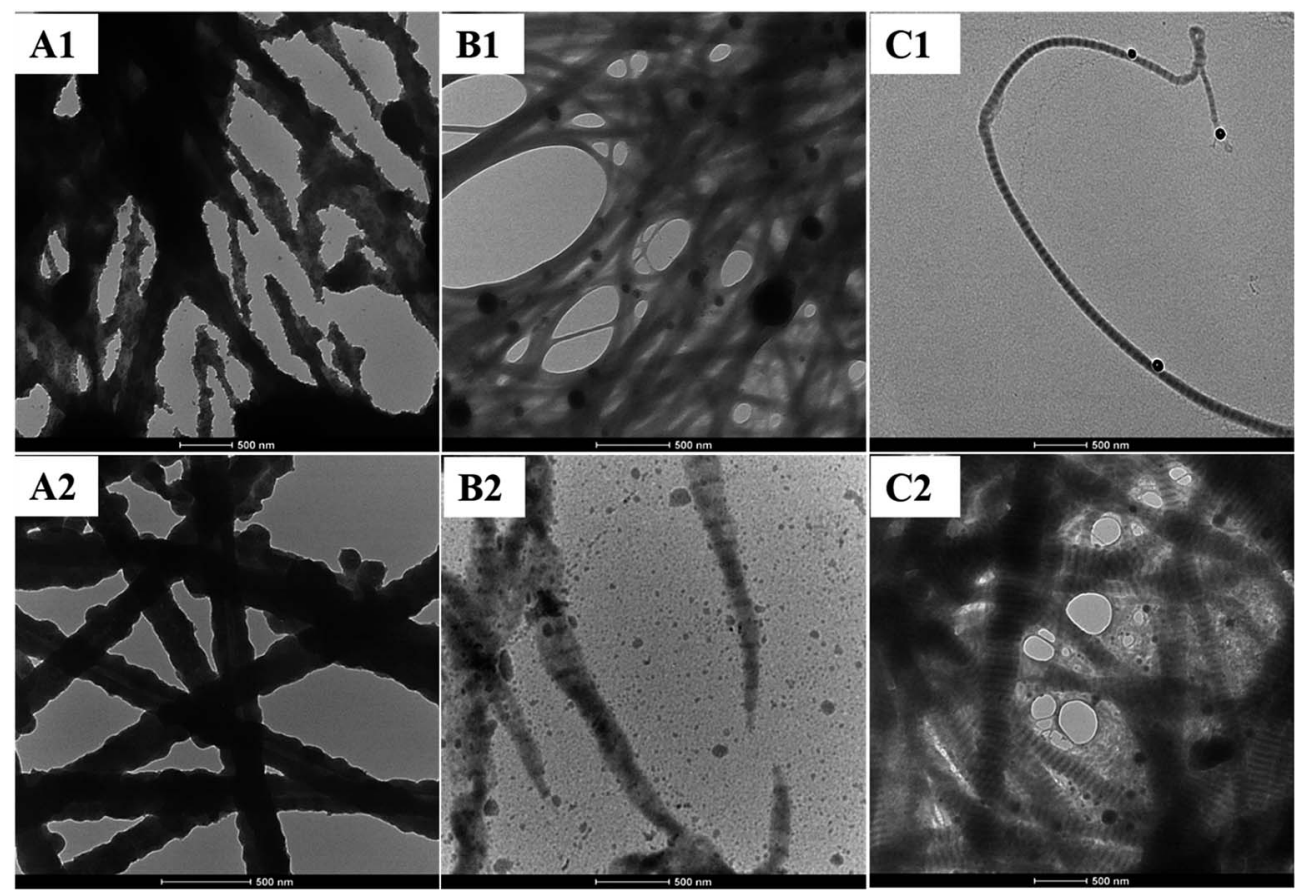

Fig. 7 Silicified collagen fibrils produced using either a two-step process (T-Col-SA (A1), T-Col-PAH-SA (B1), and T-Col-inSA (C1)) or a onestep approach (Col-SA (A2), Col-PAH-SA (B2), and Col-inSA (C2)).

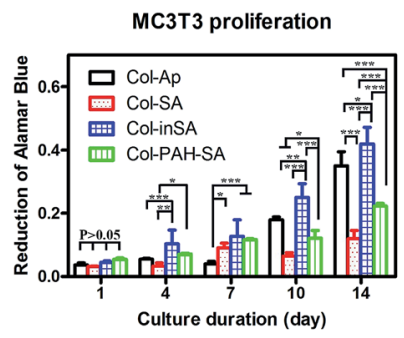

Fig. 8 Proliferation of MC3T3-E1 cells on mineralized collagen membranes: collagen-apatite (Col-Ap, control), Col-SA (SA/Col = $4: 3)$, Col-PAH-SA (SA/Col $=4: 3)$, and Col-inSA (SA/Col $=4: 3$ ) over the course of 14 days. Data is presented as mean \pm standard error Statistically significant differences $(p)$ between various groups were measured using two-way RM ANOVA analysis of variance, and *: $p<$ $0.05, * *: p<0.01, * * *: p<0.001$.

\subsection{In vitro cell culture}

Different mineralized collagen fibrous membranes were tested for their ability to support cell growth in vitro. An osteoblastic cell line MC3T3-E1 was used. Collagen-apatite (Col-Ap) matrices have been widely used as scaffolds for bone tissue engineering, thus the Col-Ap fibrous membrane was used as the control. ${ }^{36-42}$ Cell proliferation and viability on different fibrous membranes were quantified using alamarBlue assay. The Col-inSA group supports a higher proliferation rate of MC3T3-E1 cells, especially at the late stage of incubation, compared with Col-Ap, Col-SA and Col-PAH-SA (Fig. 8). This result indicates that the intrafibrillar silicified collagen fibrous membrane has a better biological response to osteoblast cells compared with Col-Ap. It is well-established that siliconinduced cell responses are dose-dependent. ${ }^{43,44}$ As shown in the TEM and SEM images of Col-inSA fibrils (Fig. 3), silica is wrapped up by collagen fibrils, demonstrating dense and obvious D-banding structures, allowing gradual release of silicon. ${ }^{45}$ Therefore, intrafibrillar silicified collagen fibril can serve as a carrier and gradually release silicon ions from the collagen fibrils to positively impact cell activities instead of burst release causing negative cell responses. ${ }^{46}$

\section{Conclusions}

We have presented a one-step collagen self-assembly/ silicification approach in preparation of intrafibrillar silicified collagen fibrils. Highly negatively charged TPP first accumulates in the positively charged gap zone of collagen fibrils due to electrostatic attraction, which further attracts positively charged fluidic PAH-SA precursors to enter the collagen fibrils. As the positive analog of the zwitterionic proteins in silicification, $\mathrm{PAH}$ promotes silica precipitation in the presence of negative analog, TPP. Thus the accumulation of PAH-SA and TPP in the gap zone of collagen fibrils facilitates the formation of silica within gap zone of collagen fibrils, resulting in intrafibrillar silicification. Moreover, the structure of the silicified collagen fibrils can be manipulated by varying silica precursors, polyanions and SA/ Col ratios to produce silicified collagen fibrils with a coreshell, twisted, or banded structure. The intrafibrillar silicified collagen fibrils possess better cell compatibility compared with the collagen-apatite fibrils. Thus, this approach provides a facile method to produce intrafibrillar silicified collagen fibrils for biomedical applications. 


\section{Disclosures}

Dr. Wei has an ownership interest in OrteoPoniX LLC, which is developing and commercializing biomaterials for orthopedic applications.

\section{Acknowledgements}

The authors would like to thank NSF grant (CBET-1347130) for its support.

\section{References}

1 C. C. Perry and T. Keeling-Tucker, J. Biol. Inorg Chem., 2000, 5, 537-550.

2 E. Beniash, Wiley Interdiscip. Rev.: Nanomed. Nanobiotechnol., 2011, 3, 47-69.

3 S. Wenzl, R. Hett, P. Richthammer and M. Sumper, Angew. Chem., 2008, 120, 1753-1756.

4 L. Niu, K. Jiao, H. Ryou, A. Diogenes, C. K. Yiu, A. Mazzoni, J. Chen, D. D. Arola, K. M. Hargreaves and D. H. Pashley, Biomacromolecules, 2013, 14, 1661-1668.

5 A. Woesz, J. C. Weaver, M. Kazanci, Y. Dauphin, J. Aizenberg, D. E. Morse and P. Fratzl, J. Mater. Res., 2006, 21, 2068-2078.

6 H. Ehrlich, R. Deutzmann, E. Brunner, E. Cappellini, H. Koon, C. Solazzo, Y. Yang, D. Ashford, J. Thomas-Oates and M. Lubeck, Nat. Chem., 2010, 2, 1084-1088.

7 A. J. Mieszawska, N. Fourligas, I. Georgakoudi, N. M. Ouhib, D. J. Belton, C. C. Perry and D. L. Kaplan, Biomaterials, 2010, 31, 8902-8910.

8 W. Zhai, H. Lu, L. Chen, X. Lin, Y. Huang, K. Dai, K. Naoki, G. Chen and J. Chang, Acta Biomater., 2012, 8, 341-349.

9 M. F. Desimone, C. Hélary, G. Mosser, M. M. GiraudGuille, J. Livage and T. Coradin, J. Mater. Chem., 2010, 20, 666-668.

10 T. Delclos, C. Aimé, E. Pouget, A. Brizard, I. Huc, M. H. Delville and R. Oda, Nano Lett., 2008, 8, 1929-1935.

11 S. Heinemann, H. Ehrlich, T. Douglas, C. Heinemann, H. Worch, W. Schatton and T. Hanke, Biomacromolecules, 2007, 8, 3452-3457.

12 N. Kröger, S. Lorenz, E. Brunner and M. Sumper, Science, 2002, 298, 584-586.

13 C. C. Lechner and C. F. Becker, Mar. Drugs, 2015, 13, 52975333.

14 M. F. Desimone, C. Hélary, I. B. Rietveld, I. Bataille, G. Mosser, M. M. Giraud-Guille, J. Livage and T. Coradin, Acta Biomater., 2010, 6, 3998-4004.

15 S. Heinemann, C. Heinemann, R. Bernhardt, A. Reinstorf, B. Nies, M. Meyer, H. Worch and T. Hanke, Acta Biomater., 2009, 5, 1979-1990.

16 S. Quignard, G. Copello, C. Aimé, I. Bataille, C. Hélary, M. F. Desimone and T. Coradin, Adv. Eng. Mater., 2012, 14, B51-B55.

17 S. Heinemann, C. Heinemann, H. Ehrlich, M. Meyer, H. Baltzer, H. Worch and T. Hanke, Adv. Eng. Mater., 2007, 9, 1061-1068.
18 S. Heinemann, H. Ehrlich, C. Knieb and T. Hanke, Int. J. Mater. Res., 2007, 98, 603-608.

19 K. Spinde, M. Kammer, K. Freyer, H. Ehrlich, J. N. Vournakis and E. Brunner, Chem. Mater., 2011, 23, 2973-2978.

20 C. Hu, L. Zhang and M. Wei, ACS Biomater. Sci. Eng., 2015, 1, 669-676.

21 C. Hu, M. Zilm and M. Wei, J. Biomed. Mater. Res., Part A, 2016, 104, 1153-1161.

22 N. Rajan, J. Habermehl, M. F. Coté, C. J. Doillon and D. Mantovani, Nat. Protoc., 2006, 1, 2753-2758.

23 L. Niu, K. Jiao, Y. Qi, C. K. Yiu, H. Ryou, D. D. Arola, J. Chen, L. Breschi, D. H. Pashley and F. R. Tay, Angew. Chem., 2011, 123, 11892-11895.

24 L. Niu, K. Jiao, H. Ryou, C. K. Yiu, J. Chen, L. Breschi, D. D. Arola, D. H. Pashley and F. R. Tay, Angew. Chem., 2013, 125, 5874-5878.

25 D. A. Cisneros, J. Friedrichs, A. Taubenberger, C. M. Franz and D. J. Muller, Small, 2007, 3, 956-963.

26 Y. Ono, Y. Kanekiyo, K. Inoue, J. Hojo, M. Nango and S. Shinkai, Chem. Lett., 1999, 475-476.

27 D. Eglin, G. Mosser, M.-M. Giraud-Guille, J. Livage and T. Coradin, Soft Matter, 2005, 1, 129-131.

28 S. Heinemann, C. Heinemann, M. Jager, J. Neunzehn, H. Wiesmann and T. Hanke, ACS Appl. Mater. Interfaces, 2011, 3, 4323-4331.

29 F. Nudelman, K. Pieterse, A. George, P. H. Bomans, H. Friedrich, L. J. Brylka, P. A. Hilbers, G. de With and N. A. Sommerdijk, Nat. Mater., 2010, 9, 1004-1009.

30 N. Kröger, R. Deutzmann and M. Sumper, Science, 1999, 286, 1129-1132.

31 N. Li, L. Niu, Y. Qi, C. K. Yiu, H. Ryou, D. D. Arola, J. Chen, D. H. Pashley and F. R. Tay, Biomaterials, 2011, 32, 87438752.

32 Y. Liu, Y. K. Kim, L. Dai, N. Li, S. O. Khan, D. H. Pashley and F. R. Tay, Biomaterials, 2011, 32, 1291-1300.

33 Y. K. Kim, L. Gu, T. E. Bryan, J. R. Kim, L. Chen, Y. Liu, J. C. Yoon, L. Breschi, D. H. Pashley and F. R. Tay, Biomaterials, 2010, 31, 6618-6627.

34 E. Brunner, K. Lutz and M. Sumper, Phys. Chem. Chem. Phys., 2004, 6, 854-857.

35 J. Fothergill, M. Li, S. A. Davis, J. A. Cunningham and S. Mann, Langmuir, 2014, 30, 14591-14596.

36 Z. Xia and M. Wei, J. Biomater. Tissue Eng., 2013, 3, 369-384. 37 Z. Xia, X. Yu, X. Jiang, H. D. Brody, D. W. Rowe and M. Wei, Acta Biomater., 2013, 9, 7308-7319.

38 Y. Pek, S. Gao, M. M. Arshad, K. Leck and J. Y. Ying, Biomaterials, 2008, 29, 4300-4305.

39 M. M. Villa, L. Wang, J. Huang, D. W. Rowe and M. Wei, J. Biomed. Mater. Res., Part B, 2015, 103, 243-253.

40 X. Yu, Z. Xia, L. Wang, F. Peng, X. Jiang, J. Huang, D. Rowe and M. Wei, J. Mater. Chem., 2012, 22, 9721-9730.

41 X. Yu, L. Wang, F. Peng, X. Jiang, Z. Xia, J. Huang, D. Rowe and M. Wei, J. Tissue Eng. Regener. Med., 2013, 7, 974983.

42 M. M. Villa, L. Wang, J. Huang, D. W. Rowe and M. Wei, J. Biomed. Mater. Res., Part B, 2015, 103, 243-253. 
43 H. A. Santos, J. Riikonen, J. Salonen, E. Mäkilä, T. Heikkilä, T. Laaksonen, L. Peltonen, V. P. Lehto and J. Hirvonen, Acta Biomater., 2010, 6, 2721-2731.

44 E. A. Bortoluzzi, L. Niu, C. D. Palani, A. R. El-Awady, B. D. Hammond, D. Pei, F. Tian, C. W. Cutler, D. H. Pashley and F. R. Tay, Dent. Mater., 2015, 31, 1510-1522.
45 L. Niu, K. Jiao, Y. Qi, S. Nikonov, C. K. Yiu, D. D. Arola, S. Gong, A. El-Marakby, M. R. Carrilho and M. W. Hamrick, FASEB J., 2012, 26, 4517-4529.

46 S. Bhattacharjee, I. M. Rietjens, M. P. Singh, T. M. Atkins, T. K. Purkait, Z. Xu, S. Regli, A. Shukaliak, R. J. Clark and B. S. Mitchell, Nanoscale, 2013, 5, 4870-4883. 